afferent discharge to the cortex. That it is not derived from cortical neurones may be deduced from the fact that it was increased at a level of anæsthesia that caused depression of the cortical response. Compared to the afferent discharge, the cortical response bears a much less direct relation to the sensory stimulus. It does not follow repetitive stimulation equally well (Fig. 2,a), and when a spontaneous spindle has just occurred, the cortical response may be impossible to identify (Fig. 2,b).

Stimuli that were most effective in evoking an afferent discharge to the cortex proved to be pressure, touch and passive movements of the fingers. Pinching was definitely less effective, even when it was quite hard.

The observation that the evoked afferent discharge to the cortex in man can be enhanced by barbiturate anæsthesia may indicate that anæsthesia suppresses an inhibitory action which checks afferent signals at a lower level. So far, no afferent discharge to the cortex has been identified in unanæsthetized subjects. It is not unlikely, however, that improvements in technique will make this possible. That would enable one to determine whether distraction of attention in man can influence the afferent transmission at subcortical levels.

\section{K.-E. Hagbarth}

S. HÖJEBERG

Neurosurgical Clinic and

Department of Clinical Neurophysiology,

Serafimerlasarettet, Stockholm K. Nov. 30.

1 Hagbarth, K.-E., and Kerr, D. I. B., J. Neurophysiol., 17, 295 (1954). 2 Hernández-Peón, R., Acta Neurol. Latinoamer., 1, 256 (1955).

"Adrian, E. D., in "Brain Mechanisms and Consciousness". edit. by Lord Adrian, Bremer, F.,
Scl. Pub., Oxford, 1954).

\section{Effect of Temperature on the Degeneration of Nerve Fibres}

IN 1950 Armstrong $^{1}$ found that the period after injury during which a nerve fibre preserves a normal histological appearance may be surprisingly long in a poikilothermic animal kept at room temperature $\left(15^{\circ}-20^{\circ} \mathrm{C}.\right)$, but that the rate of degeneration is increased and the time after which the fibre eventually disappears is shortened by a comparatively small rise in temperature. This temperature effect is important, since one of the commonest methods for investigating pathways and connexions in the nervous system involves the interpretation of degenerative changes which follow experimental injury, and it is essential to know how long one must wait before it is possible to say that surviving nerve fibres, normal in appearance, cannot have been affected by the injury.

Experiments have been carried out on the lateral popliteal nerve of a poikilothermic animal (Lacerta viridis) to investigate the temperature effect in greater detail. The nerve was cut and the animals kept in three groups in cages in which the air temperature was maintained within a few degrees of $13^{\circ} \mathrm{C}$., $20^{\circ} \mathrm{C}$. and $35^{\circ} \mathrm{C}$., respectively. Cloacal temperatures in the animals, measured with a thermocouple, were always found to approximate very closely to the air temperature.

In animals kept at $13^{\circ} \mathrm{C}$., no changes in the myelin sheaths of fibres could be observed up to three weeks after section of the nerve, although by that time about half the axons present showed irregularity of calibre, vacuolation and, in the case of a few, fragmentation. It is important to emphasize, however, that about half the axons present still preserved a normal appearance in silver preparations (Bodian's method), although there was no doubt they had been cut from their cells of origin.

The condition found in cut nerves kept for twentyone days at $13^{\circ} \mathrm{C}$. is found after three days at $20^{\circ} \mathrm{C}$. The majority of the fibres are still normal in appearance (both sheaths and axons) but a proportion show early degenerative changes. Even after twentyone days at $20^{\circ} \mathrm{C}$., a few fibres can be found in which both axon and sheath present a normal appearance. One would be tempted to conclude that the nerve must contain fibres which had not been cut; but this conclusion would almost certainly be wrong, since in animals kept at $35^{\circ} \mathrm{C}$., with one exception, no normal fibres could be found five days or more after section of the nerve. The exception was an animal in which one apparently intact axon was found after seven days. In these animals (kept at $35^{\circ} \mathrm{C}$.) not only were the histological signs of degeneration both in the sheaths and the axons virtually uniform in all fibres by about the fifth day, but also by the tenth day the removal of degenerated myelin was in an advanced stage, and practically complete by twenty-one days.

It may be concluded that for reliable interpretation, experiments on poikilothermic animals which involve the degeneration of nerve fibres should be carried out at temperatures which approximate to the body temperature of homoiothermic mammals. At ordinary room temperature in Britain, some nerve fibres may retain a normal histological appearance for three weeks and probably considerably longer after they have been cut. The question why a proportion of the fibres only should be resistant to change is an interesting one; the calibre of the fibre does not seem to be relevant, since both coarse and fine fibres may show this characteristic; but our experiments throw no further light on the problem. It must be noted also that the experiments are relevant only to the peripheral nervous system. Armstrong's ${ }^{2}$ work suggests that in the central nervous system injured fibres may preserve a normal appearance for even longer periods, and this is a matter which requires further investigation.

Finally, it may be added that in a parallel series of experiments in which the nerve was crushed but not cut, evidence was obtained that at higher temperatures the rate of regeneration was accelerated to about the same extent as the rate of degeneration. The effect of temperature on regeneration has been studied in detail by Lubinska and Olekiewicz in amphibians using physiological methods to estimate the rate of fibre growth. Our own experiments, using histological methods, are in accord with theirs.

$$
\begin{aligned}
& \text { H. J. GambIe } \\
& \text { F. GoldBy } \\
& \text { G. M. R. SMITH }
\end{aligned}
$$

Department of Anatomy,

St. Mary's Hospital Medical School. Dec. 20.

${ }^{1}$ Armstrong, J. A., J. Anat., Lond., 84, 146 (1950).

armstrong, J. A., J. Anat., Lond., 86, 277 (1951).

s Lubinska, L., and Olekiewicz, M., Acta Biol. Exp., Varsovie, 16, 125 $(1950)$. 